in vivo $35: 845-857(2021)$

doi:10.21873/invivo.12325

\title{
Therapeutic Effects of Tonsil-derived Mesenchymal Stem Cells in an Atopic Dermatitis Mouse Model
}

\author{
HARRY JUNG ${ }^{1}$, GIL MYEONG SON ${ }^{2}$, JAE JUN LEE ${ }^{3}$ and HAE SANG PARK ${ }^{1,2}$ \\ ${ }^{1}$ Institute of New Frontier Research Team, Hallym University, \\ Hallym Clinical and Translation Science Institute, Chuncheon, Republic of Korea; \\ ${ }^{2}$ Department of Otorhinolaryngology-Head and Neck Surgery, Chuncheon Sacred Heart Hospital, \\ College of Medicine, Hallym University, Chuncheon, Republic of Korea; \\ ${ }^{3}$ Department of Anesthesiology and Pain Medicine, College of Medicine, \\ Hallym University, Chuncheon, Republic of Korea;
}

\begin{abstract}
Background/Aim: Mesenchymal stem cells (MSCs) have been suggested as an alternative therapeutic option in atopic dermatitis. Palatine tonsils are lymphoepithelial tissue located around the oropharynx and have been proposed as one of the important alternative sources of MSCs. The purpose of this study was to evaluate the protective and therapeutic effects of tonsil-derived MSCs (TMSCs) in a 2,4-dinitrofluorobenzene (DNFB)-induced mouse model of atopic dermatitis (AD). Materials and Methods: The effect of TMSCs was evaluated in 20 $C 57 B L / 6 J$ mice that were randomly divided into four groups (normal, DNFB-PBS, DNFB-TMSC7, and DNFB-TMSC16 group). TMSCs were subcutaneously injected into DNFBsensitized mice on day 7 (DNFB-TMSC7 group) and day 16 (DNFB-TMSC16 group). Several parameters of inflammation were assessed. Results: Subcutaneously injected TMSCS significantly improved the inflammatory symptoms in a DNFB-induced AD model mice, particularly showing therapeutic effects rather than protective effects. TMSC treatment inhibited T-cell-mediated inflammatory responses by decreasing the levels of IL-6,IL-1 $\beta, T N F-\alpha$ (Th1 cell marker), IL-4 (Th2 cell marker), and B-cell-mediated serum $\mathrm{IgE}$. In contrast, TMSCs enhanced the anti-inflammatory cytokine TGF- $\beta$. Conclusion: In vitro and in vivo results suggest that TMSC treatment improved inflammatory skin
\end{abstract}

This article is freely accessible online.

Correspondence to: Hae Sang Park, MD, Ph.D., Department of Otorhinolaryngology-Head and Neck Surgery, Chuncheon Sacred Heart Hospital, College of Medicine, Hallym University, 77, Sakjuro, Chuncheon, Gangwon-do 24253, Republic of Korea. Tel: +82 332405181, Fax: +82 332412909, e-mail: hs-piao@hanmail.net

Key Words: Stem cells, tonsil, atopic dermatitis. lesions in the DNFB-induced $A D$ mice model via immunomodulatory effects of the TMSCs. TMSCs inhibit Tcell and B-cell mediated responses, and enhance the antiinflammatory responses.

Atopic dermatitis (AD) is a chronic inflammatory disease of the skin characterized by relapsing eczematous skin lesions with severe pruritus that impairs the quality of life $(1,2)$. AD affects $10-20 \%$ of children worldwide, and its incidence is increasing in industrialized countries (3). AD has multiple etiologies including genetic susceptibility, disruption of the epidermal barrier, and immune system dysregulation (2). The pathogenesis of AD is characterized by excessive Th2derived inflammatory responses, resulting in elevated serum IgE levels and blood eosinophils $(1,4)$. Although AD has been described as a Th2-dominant disease, several studies have shown that $\mathrm{AD}$ is not exclusively explained by the Th2 immune response. AD is a biphasic inflammatory skin disorder (acute, chronic). The acute AD skin lesions show Th2 inflammation characterized by the infiltration of CD4+ T cells. Subsequently, the chronic phase demonstrates a Th1type immune response $(3,5)$. Furthermore, recent studies showed that Th1, Th17, and Th22 might contribute to the pathogenesis of $\operatorname{AD}(4,6)$.

Mesenchymal stem cell (MSC)-based therapy has been reported to regulate excessive inflammatory reactions in various autoimmune and inflammation-related diseases including graft-versus-host disease, inflammatory bowel disease, rheumatoid arthritis, and type I diabetes (7-9). Additionally, several studies revealed that MSCs can also improve allergic symptoms in asthma, allergic rhinitis, and dermatitis $(10,11)$. In general, bone marrow-derived MSCs have been widely used in research and for therapeutic purposes. However, they can also be successfully isolated from many other mesodermal tissues $(12,13)$. Palatine tonsils are lymphoepithelial tissue located around the 


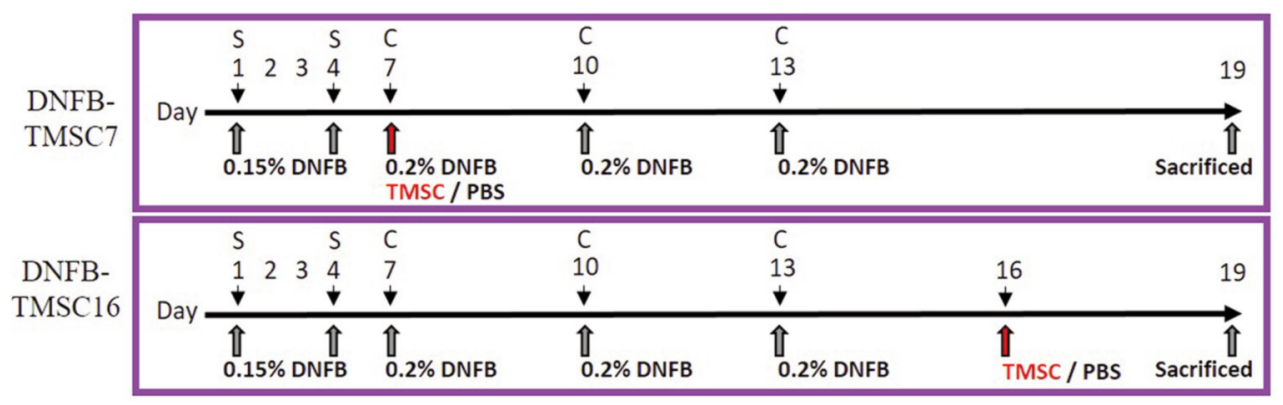

Figure 1. Experimental scheme for the DNFB-induced AD model. On day 0 and 4, the mice were sensitized with $100 \mu$ of $0.15 \%$ DNFB at their shaved back and ear. On days 7, 10, and 13, sensitized mice were challenged with $0.2 \%$ DNFB. DNFB-induced AD mice were treated with TMSC on day 7 (DNFB-TMSC7 group) and on day 16 (DNFB-TMSC16 group). DNFB: 2,4-Dinitrofluorobenzene; S: sensitization; C: challenge; TMSC: tonsil-derived mesenchymal stem cells.

oropharynx and have been proposed as one of the important alternative sources of MSCs because of several advantages, which include the simple surgical process used to obtain the tissues $(13,14)$. Recently, tonsil-derived MSCs (TMSCs) showed therapeutic efficacy in allergic and autoimmune diseases such as allergic rhinitis and psoriasis by suppressing Th2 and Th17 responses $(11,15)$.

The purpose of this study was to investigate the protective and therapeutic effects of TMSCs in a 2,4-dinitrofluorobenzene (DNFB)-induced mouse model of $\mathrm{AD}$ at two different administration times, the day of the first DNFB challenge (day 7), and three days after the final DNFB challenge (day 16). Adipose tissue- and umbilical cord-derived MSCs were proposed as a therapeutic modality for AD in recent studies $(1,10,16)$. However, to the best of our knowledge, this was the first study to demonstrate the efficacy of TMSCs in an AD mouse model. Several studies reported that repeated 2,4,6-trinitrochlorobenzene (TNCB) or DNFB application to mice skin induced AD-like clinical symptoms similar to those of $\mathrm{AD}$ in humans $(3,7,17-19)$. Therefore, we evaluated the efficacy of TMSCs in AD using a wellestablished mouse model.

\section{Materials and Methods}

Preparation and culture of TMSCs. TMSCs were isolated and cultured according to a previously described method (13). The study protocol was approved by the Institutional Review Board of Hallym University Medical Center (2016-41). The patients or their legal guardians provided written informed consent to participate. Tonsillar tissue was obtained from a ten-year-old girl who underwent a tonsillectomy. The tonsillar tissue was minced and digested for $30 \mathrm{~min}$ at $37^{\circ} \mathrm{C}$ in high-glucose $(4500 \mathrm{mg} / \mathrm{l})$ Dulbecco Modified Eagle's Medium (DMEM) (Welgene Inc., Gyeongsan, Republic of Korea) containing $10 \mathrm{mg} / \mathrm{ml}$ DNase (Sigma Aldrich, St. Louis, MO, USA) and $210 \mathrm{U} / \mathrm{ml}$ collagenase type I (Invitrogen, Carlsbad, CA, USA). The digested tissue was filtered through a wire mesh, and the cells were washed twice in high-glucose DMEM/20\% fetal bovine serum (FBS) (Welgene Inc., Gyeongsan,
Republic of Korea) and additional times in high-glucose DMEM/10\% FBS. Ficoll-Paque (GE Healthcare, Little Chalfont, UK) density gradient centrifugation was used to obtain mononuclear cells. The cells $\left(1 \times 10^{6}\right)$ were plated in a $100-\mathrm{mm}$ culture dish in high-glucose DMEM, 10\% FBS, and $100 \mathrm{U} / \mathrm{ml}$ penicillin/streptomycin (Gibco, Grand Island, NY, USA). The nonadherent cells were removed after $48 \mathrm{~h}$, and fresh culture medium was added to the adherent mononuclear cells (TMSCs). TMSCs at passage 5 were used for the experiments.

Allergen sensitization and challenge. This study was approved by the Institutional Review Board of Hallym University (Hallym 201974), Chuncheon, Republic of Korea. Twenty male C57BL/6J mice were used in this study. DNFB sensitization was achieved by applying $25 \mu \mathrm{l}$ of $0.15 \%$ DNFB in acetone/olive oil at a ratio of $3: 1$ to the outer and inner surfaces of the right ears. The same solution $(100 \mu \mathrm{l})$ was applied to shaved dorsal skin on days 1 and 4 . The sensitized mice were challenged by applying $0.2 \%$ DNFB to the dorsal and ear skin on days 7, 10, and 13 (Figure 1).

TMSC treatment. The mice were randomly divided into four groups: (1) normal $(\mathrm{n}=5)$; (2) DNFB-PBS (control group, $\mathrm{n}=5$ ); (3) DNFBTMSC7 $(n=5)$; and (4) DNFB-TMSC16 $(n=5)$. TMSCs $\left(2 \times 10^{4}\right)$ in growth medium were mixed with Matrigel ${ }^{\circledR}$ (MA, BD Biosciences, San Jose, CA, USA) at a ratio of 1:2 to produce a final volume of $200 \mu 1$. TMSC-embedded MA $(200 \mu \mathrm{l})$ was injected into the subcutaneous tissue around the dorsal skin lesion in the DNFBTMSC7 group on day 7 using a 26-gauge sterile needle syringe. The DNFB-TMSC16 group was treated with the same volume of TMSC-embedded MA on day 16 and the DNFB-PBS group received the same volume of PBS.

\section{Assessments}

Histological analysis. All mice were euthanized on day 19 in compliance with the Animal Experiment Guidelines of the Hallym University Medical Research Institute. Ear and skin tissue samples were embedded in paraffin blocks and sectioned into $10-\mu \mathrm{m}$-thick slices. The sections were stained with hematoxylin and eosin (H\&E) and toluidine blue according to protocols described by IHCWORLD (ihcworld.com). The thickness of the ear and the skin epidermis were measured using the ImageJ software (ImageJ $1.49 \mathrm{v}$, National Institute of Health, Bethesda, MD, USA). Before euthanization and 
under anesthesia, the spleen and inguinal lymph nodes were removed from all mice and weighed immediately (Tuning-fork vibration system, SHINKO DENSHI CO., LTD. Bunkyo-Ku, Tokyo, Japan).

In vivo tracking. A PKH26 red fluorescent cell linker (Sigma) was used to label the TMSC cell membranes. The TMSCs $\left(2 \times 10^{4}\right)$ were mixed with PKH26 solution and incubated for 5 min. Labeling was stopped with $1 \%$ bovine serum albumin (BSA, Bovogen Biologicals Pty Ltd., East Keilor, Australia) and the cells were washed with 10\% DMEM. TMSCs labeled with PKH26 were injected into the subcutaneous tissue around the dorsal skin lesion using a 26-gauge sterile needle syringe in the TMSC groups. The skin tissue was harvested on day 19 and examined by fluorescence microscopy (Leica, Germany). For nuclear counterstaining, the sectioned skin tissues were incubated for 2 min with $10 \mu \mathrm{g} / \mathrm{ml} \mathrm{4}$ '6-diamidino-2phenylindole (DAPI) (Invitrogen) reagent in PBS. The cells were observed by fluorescence microscopy (Carl Zeiss Microscopy GmbH, Zeiss, Germany) under 200-fold magnification.

Immunohistochemical analysis. The sectioned tissue slides were dried in an oven for $30 \mathrm{~min}$ at $60^{\circ} \mathrm{C}$. The deparaffinized tissues were denatured by microwaving in $10 \mathrm{mM}$ Tris- $\mathrm{Hcl}$ and $1 \mathrm{mM}$ EDTA $(\mathrm{pH}$ 9.0 ) and then blocked in $2 \%$ horse serum for $60 \mathrm{~min}$. The slides were incubated in diluted primary antibodies for $12 \mathrm{~h}$ at $25^{\circ} \mathrm{C}$, treated with $0.3 \%$ hydrogen peroxide in $1 \mathrm{x}$ PBS for $10 \mathrm{~min}$, and incubated with horseradish peroxidase (HRP)-conjugated secondary antibody. HRP activity was detected with the 3,3'-diaminobenzidine (DAB) substrate. The slides were washed in PBS three times for 5 min each and counterstained with Mayer's hematoxylin. The primary antibodies used were anti-TGF- $\beta 1$ (1:100, Abcam, Cambridge, UK), TNF- $\alpha$ (1:50, Santa Cruz Biotechnology, Inc., Dallas, TX, USA), interleukin 6 (1:50, Santa Cruz Biotechnology, Inc.), and interleukin 4 (1:50 Santa Cruz Biotechnology). The secondary antibodies used were goat anti-mouse $\operatorname{IgG}(1: 250$, Thermo Fisher Scientific Inc., Waltham, MA, USA) and goat antirabbit IgG (1:250, Thermo Fisher Scientific). The stained skin tissues were observed by light microscopy (Carl Zeiss Microscopy $\mathrm{GmbH})$. The immunopositive cells were measured using ImageJ (National Institute of Health).

Measurement of total serum IgE. Serum was prepared from whole blood by centrifugation at $1,000 \times g$ for $15 \mathrm{~min}$. Capture antibody was coated on 96 -well flat-bottom plates for $12 \mathrm{~h}$ at $4{ }^{\circ} \mathrm{C}$. The coated plates were washed and blocked with $10 \%$ FBS for $1 \mathrm{~h}$ at room temperature. Serial dilutions of the standard $(1.6,3.1,6.3$, $12.5,25,50$, and $100 \mathrm{ng} / \mathrm{ml})$ and samples $(1: 2$ and $1: 4)$ were incubated for $2 \mathrm{~h}$ at room temperature. The absorbance of the reactions was read at $450 \mathrm{~nm}$ within $30 \mathrm{~min}$ on a GloMax ${ }^{\circledR}$ Discover Microplate Reader (Madison, WI, USA). All procedures were performed in the dark.

Terminal-deoxynucleotidyl transferase-mediated nick end-labeling (TUNEL) assay. The slides were washed twice with fresh xylene (5 min each time), rehydrated in a graded ethanol series [absolute ethanol (100\%) twice for $5 \mathrm{~min}$, then $95 \%, 70 \%$, and $50 \%$ ethanol each for $5 \mathrm{~min}$ ], and rinsed in PBS for $5 \mathrm{~min}$. The samples were permeabilized in proteinase $\mathrm{K}$ for $15 \mathrm{~min}$ at room temperature and rinsed in PBS three times for $5 \mathrm{~min}$. The terminal deoxynucleotidyl transferase dUTP nick-end labeling (TUNEL) In situ Cell Death
Detection Kit (Roche, Indianapolis, IN, USA) was used according to the manufacturer's instructions. The slides were counterstained with $1 \mu \mathrm{g} / \mathrm{ml}$ DAPI (Invitrogen), incubated for another $10 \mathrm{~min}$, rinsed in PBS three times for $5 \mathrm{~min}$, and then sealed. A fluorescence scanning microscope (Olympus, Tokyo, Japan) was used to assess the fluorescence.

LPS-induced inflammatory response. NIH3T3 mouse embryo fibroblast cells were obtained from Hallym University (Chuncheon, Republic of Korea), and cultured in DMEM with $10 \% \mathrm{FBS}$ in $5 \% \mathrm{CO}_{2}$ at $37^{\circ} \mathrm{C}$. The TMSCs were stimulated with $25 \mathrm{ng}$ of lipopolysaccharide (LPS) in triplicate for $6 \mathrm{~h}$. To determine the relative levels of TNFalpha, IL-6, and IL-1 $\beta$ RNA transcripts, the cells were harvested using easy-BLUE (iNtRON Biotechnology, Gyeonggi-do, Republic of Korea) reagent and cDNA was synthesized according to the manufacturer's instructions (iNtRON Biotechnology, Gyeonggi-do, Republic of Korea). cDNA was amplified by polymerase chain reaction (PCR) in a final reaction volume of $20 \mu$ using Power SYBR Green PCR Master Mix (Thermo Fisher Scientific Inc.) and 10 pmol of primer (TNF- $\alpha$ sense primer: GTTCTGTCCCTTTCACTCACTG, anti-sense primer: GGTAGAGAATGGATGAACACC; IL-6 sense primer: CTAAGGACGGAGAGTCAGT, anti-sense primer: CTGTC GTCGATGAGATTATG; IL- $1 \beta$ sense primer: CTGTCCTGATGAGA GCATCC, anti-sense primer: TGTCCATTGAGGTGGAGAGC; and GAPDH sense primer: ACCACAGTCCATGCCATCAC and antisense primer: TGGACCACCCTGTTGCTGTA).

Statistical analysis. All data are presented as the mean \pm standard deviation. Statistical analyses were performed using the Statistical Package for Social Science software program (SPSS) (SPSS Inc., Chicago, IL, USA). $p$-Values were generated by the Student's $t$-test, with statistical significance set at $* p<0.05,{ }^{*} p<0.01$, and $* * * p<0.005$.

Ethical approval. Informed written consent was obtained from the legal guardians of all patients who participated in this study, and the study protocol was approved by the institutional review board of Hallym University Medical Center (2016-41). Animal studies were performed after receiving approval of the Institutional review board of Hallym University (Hallym 2019-74), Chuncheon, Republic of Korea.

\section{Results}

Gross analysis. To determine whether TMSCs could inhibit $\mathrm{AD}$ in mice, we induced AD-like skin lesions using DNFB and treated the mice with or without TMSCs (Figure 1). Figure 2a shows that TMSC treatment improved skin inflammation. Compared to the normal group, the DNFBPBS group showed AD-like skin lesions, which exhibited as dried skin patches and scaling. The DNFB-TMSC7 group exhibited more severe eczematous skin lesions than the DNFB-PBS group on day 7 (before the subcutaneous administration of TMSCs). However, the lesional subcutaneous injection of TMSCs on day 7 enhanced the clinical severity of the DNFB-TMSC7 group compared to the DNFB-PBS group (Day 10). The DNFB-TMSC16 group also showed eczematous patches with scaling until day 16 , before TMSC treatment. However, on day 19, these skin lesions were improved after TMSC administration. To 
a

a

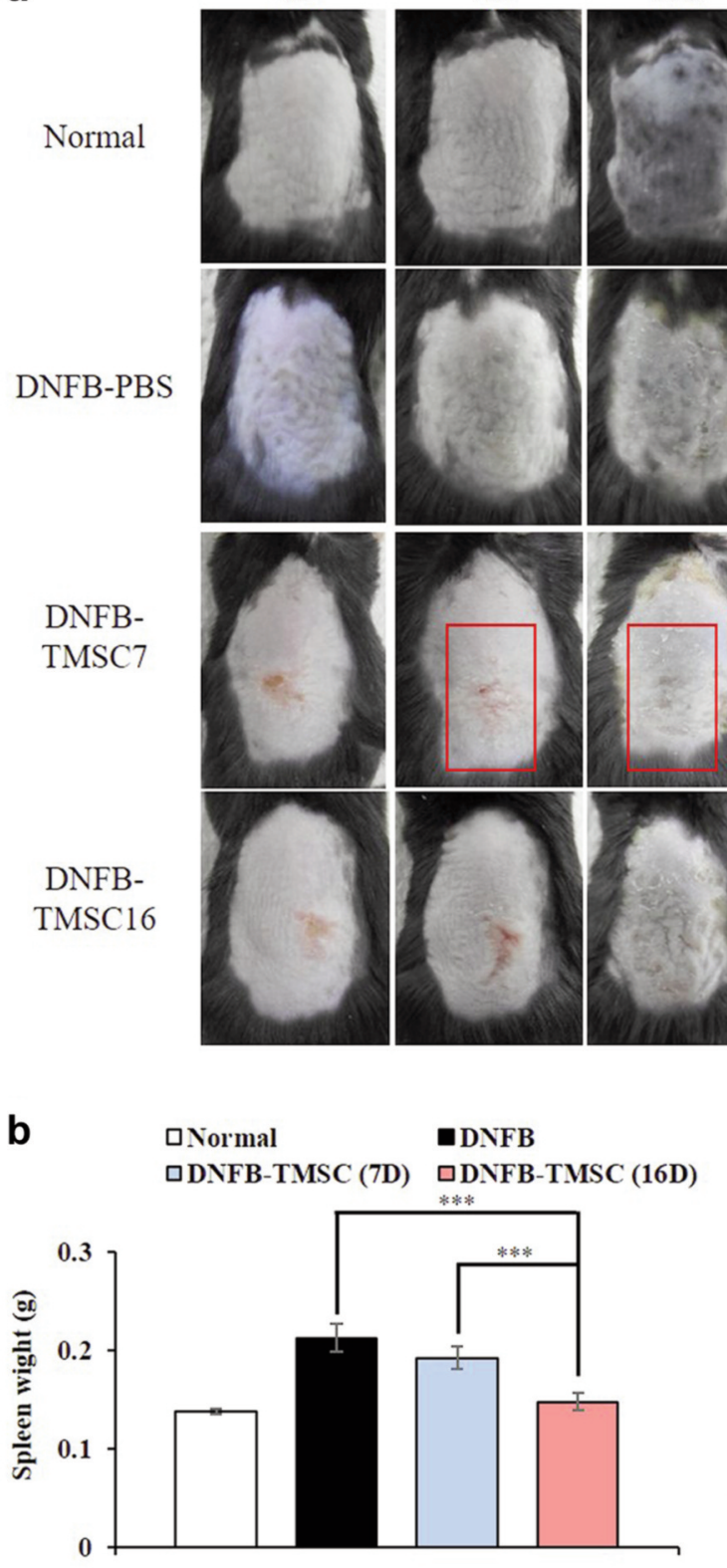

$13 \mathrm{D}$

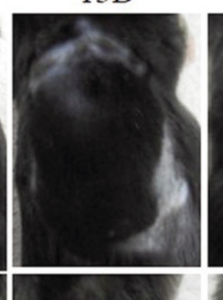

$16 \mathrm{D}$
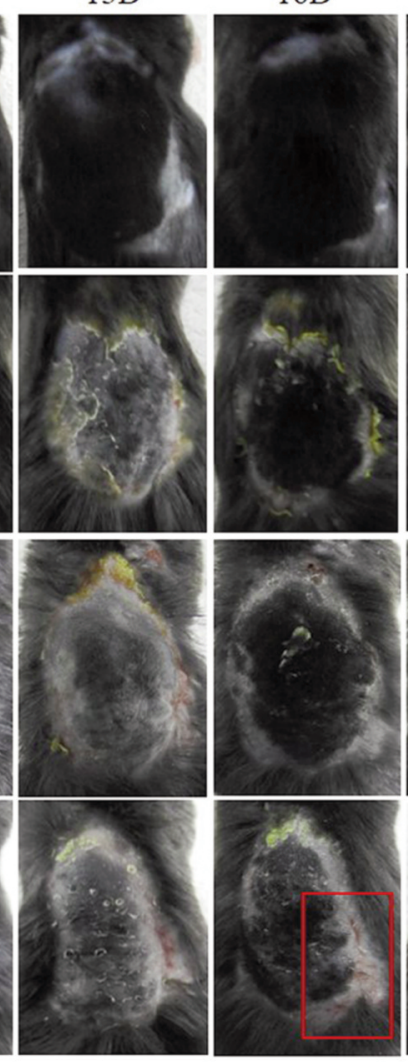

םNormal

口DNFB-TMSC (7D)
19D
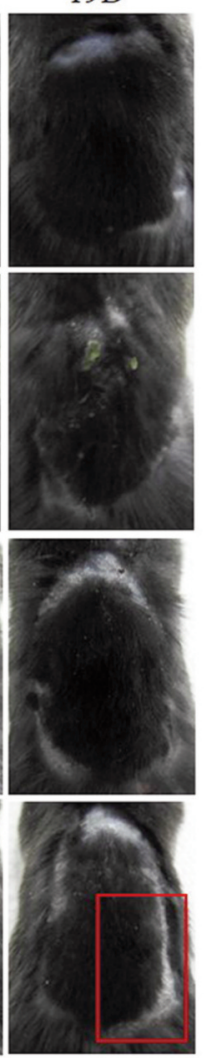

-DNFB

口DNFB-TMSC (16D)

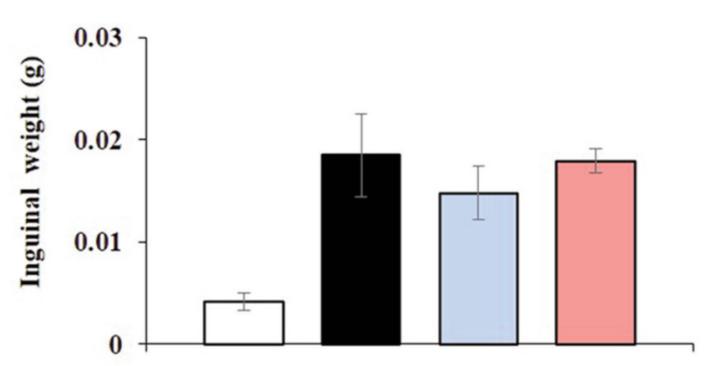

Figure 2. (a) Representative photographs taken on day 4, 7, 10,13,16 and 19. (b) Weight of the harvested spleen and inguinal lymph nodes. Increased spleen weight in the DNFB-PBS group was decreased in response to TMSCs treatment. DNFB: 2,4-dinitrofluorobenzene. TMSC: Tonsilderived mesenchymal stem cells. ${ }^{* *} p<0.005$.

evaluate the protective effect of TMSCs on AD skin lesions, we compared the DNFB-PBS and DNFB-TMSC7 groups. On day 10 , three days after TMSC treatment, the skin lesions of the DNFB-TMSC7 group were significantly improved compared to the DNFB-PBS group. The eczematous skin lesions were ameliorated in the DNFB-TMSC7 group, whereas the DNFB-PBS group showed scaling and dried skin patches with thickening of the skin. Although scaling and focal eczematous lesions were observed again in the
DNFB-TMSC7 group on days 13, 16, and 19 because of repetitive DNFB challenges, the overall clinical severity was alleviated compared to the DNFB-PBS group.

It is well known that the weights of some immune organs such as the spleen and lymph nodes increase in response to the topical application of agents with allergenic or sensitizing potential (20). As shown in Figure $2 b$, an increased spleen weight was seen in the DNFB-PBS group but the spleen weights in the groups treated with TMSCs were lower. 
a

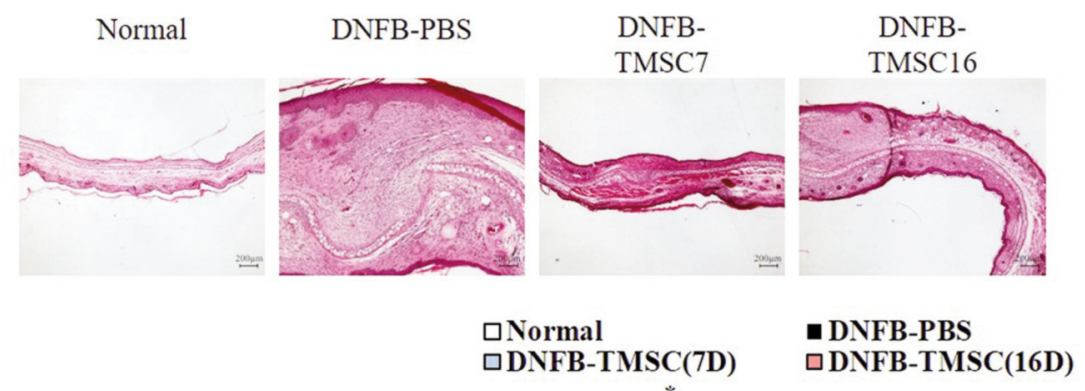

b

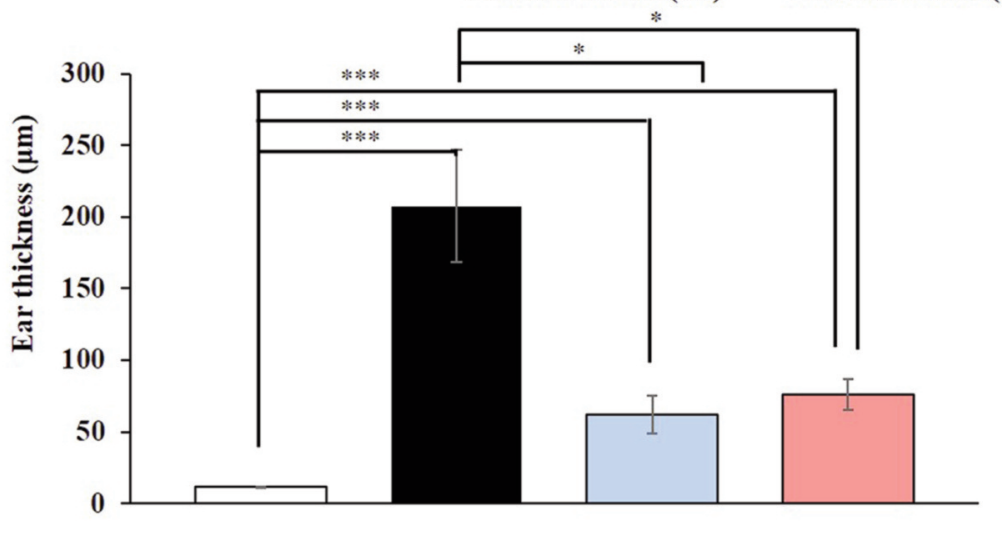

C

$$
\text { Normal }
$$

$$
\text { DNFB-PBS }
$$

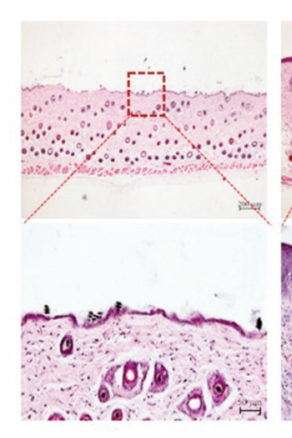

d

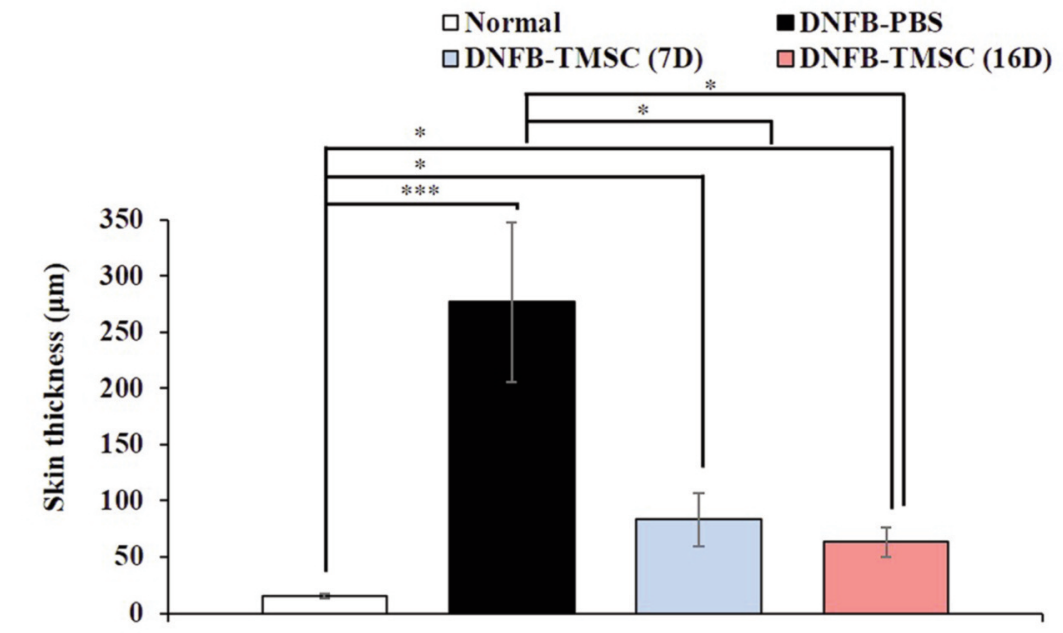

DNFB-

TMSC 16
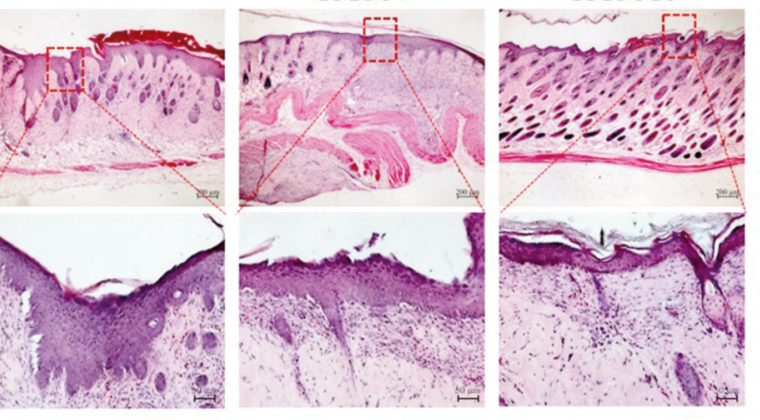
a

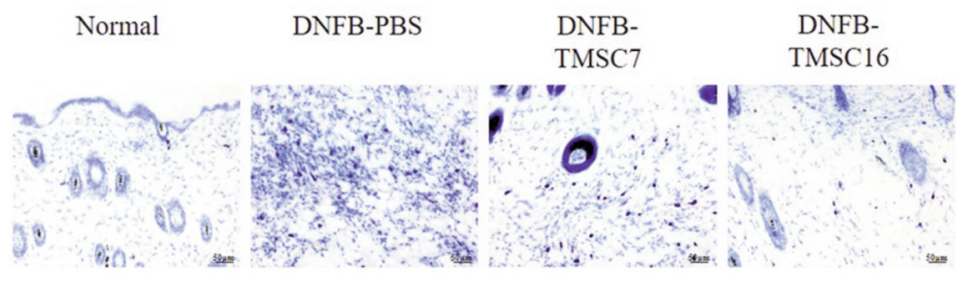

b
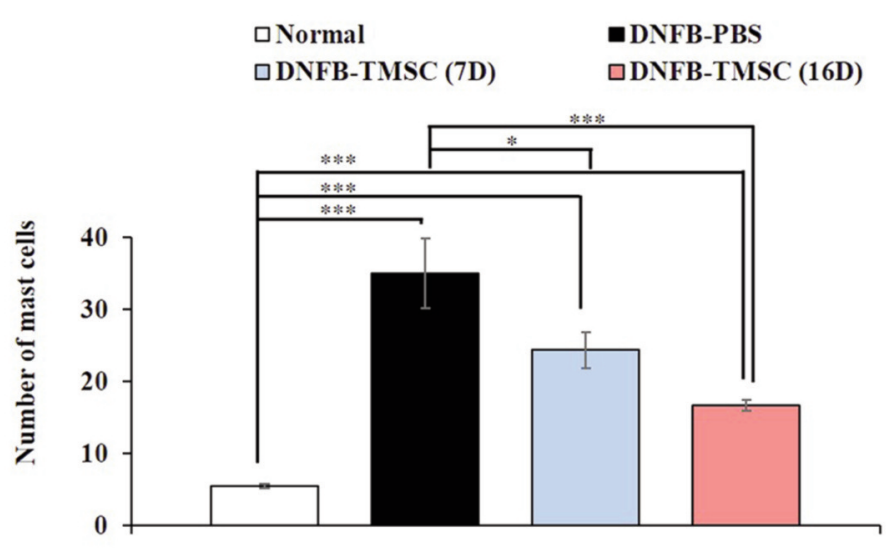

C

Normal

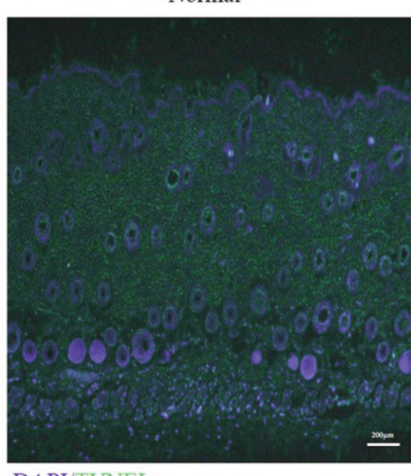

DAPI/TUNEL
DNFB-PBS
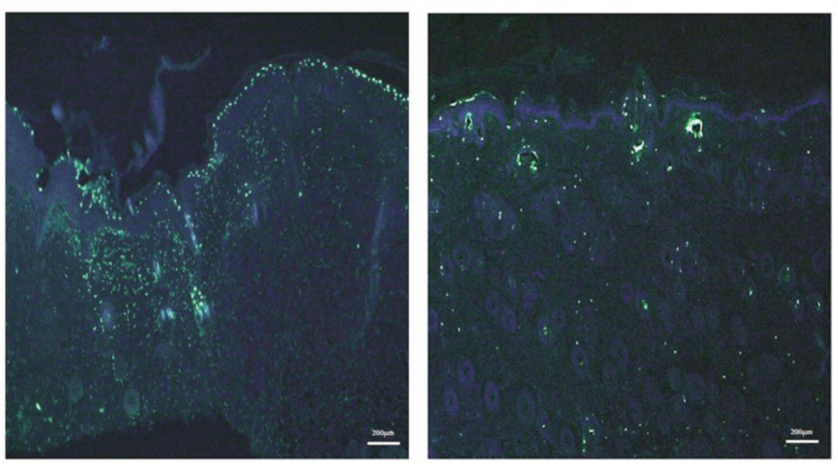

DNFB-PBS

口DNFB-TMSC (16D) $\square$ Normal

口DNFB-TMSC (7D)

d

DNFB-TMSC7

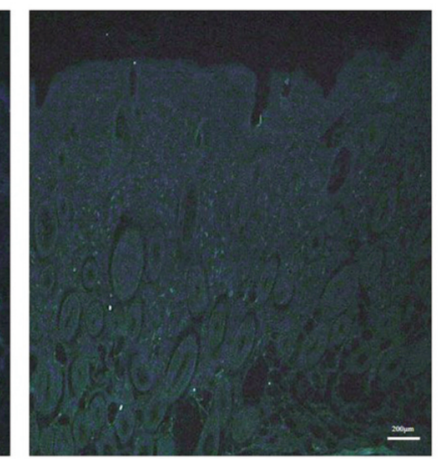

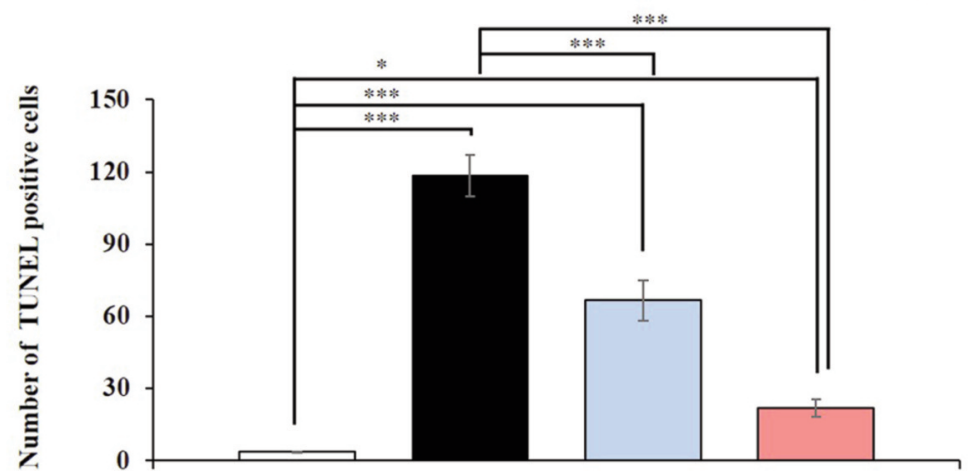

Figure 4. Reduced mast cell infiltration in dorsal skin of the TMSCs treated AD mice. (c, d) TUNEL assay of the dorsal skin lesion on day 19. Bar $=50 \mu \mathrm{m}($ a), Bar=200 $\mu \mathrm{m}(\mathrm{c})$. DNFB: 2,4-dinitrofluorobenzene; TMSC: tonsil-derived mesenchymal stem cell. *p<0.05, ***p<0.005. 


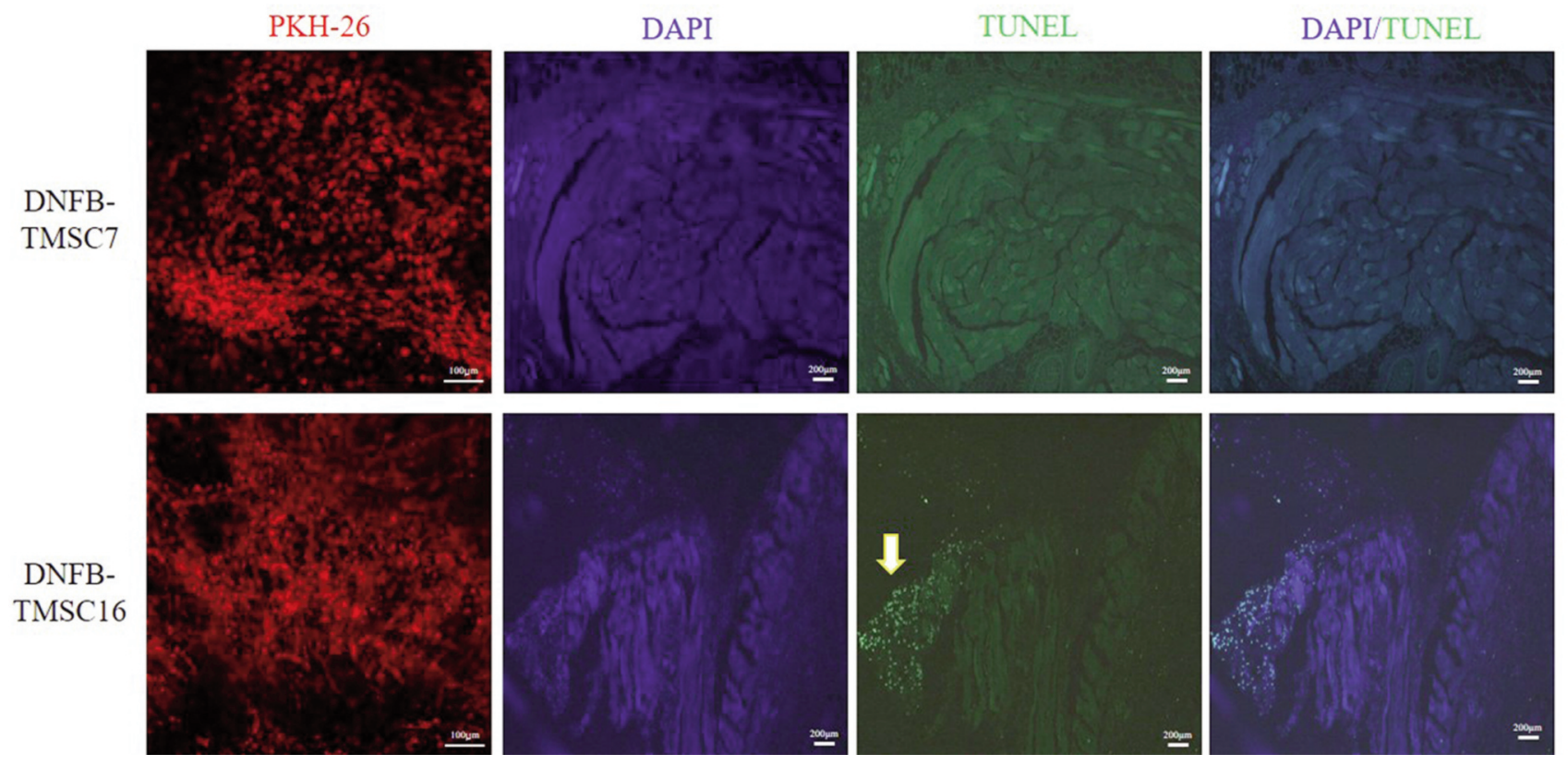

Figure 5. PKH26 tracking and TMSC viability on DNFB-induced AD model on day 19. Bar=100 $\mu \mathrm{m}$ (PKH-26), Bar=200 $\mu \mathrm{m}$ (DAPI, TUNEL, DAPI/TUNEL). DNFB: 2,4-Dinitrofluorobenzene; TMSC: tonsil-derived mesenchymal stem cell.

Notably, DNFB-TMSC16 demonstrated significantly decreased spleen weight compared to the DNFB-PBS and DNFBTMSC7 groups. The weight of the inguinal lymph nodes was also decreased in the TMSC treatment groups compared to the DNFB-PBS group but the difference was not significant.

Histological analysis. Histologic evaluation of the right ear revealed that the ear thickness was significantly increased in the DNFB-PBS group compared to the other groups (normal, DNFB-TMSC7, and DNFB-TMSC16). The DNFB-PBS group showed epidermal and dermal hyperplasia with the infiltration of inflammatory cells. However, TMSC treatment on day 7 and 16 significantly reduced the DNFB-induced ear thickness increases $(p<0.05)$ (Figure 3a, b). H\&E staining of the dorsal skin revealed that the epidermal hyperplasia seen in the DNFB-PBS group was attenuated by TMSC treatment (Figure $3 \mathrm{c}$ and d). Epidermal thickness in the DNFB-TMSC7 and DNFB-TMSC16 groups was significantly decreased compared to the DNFB-PBS group $(p<0.05)$. We next performed toluidine blue staining to determine the degranulation of mast cells infiltrating the skin lesions (Figure 4a and b). Increased mast cell infiltration was observed in the dorsal skin of the DNFB-PBS group compared to the control group $(p<0.005)$. However, significantly decreased mast cell infiltration was observed in the DNFB-TMSC7 $(p<0.05)$ and DNFB-TMSC16 $(p<0.005)$ groups compared to DNFB-PBS group. The TUNEL assay was used to investigate cell death (Figure 4c and $\mathrm{d}$ ). In the DNFB-PBS group, TUNEL-positive cells (green) were observed in the epidermis and dermis. However, the number of TUNEL-positive cells was decreased in the DNFB-TMSC7 and DNFB-TMSC16 groups compared to the DNFB-PBS group $(p<0.005)$.

In vivo tracking of injected TMSCs. We monitored the localization of the injected TMSC-PKH26 cells to evaluate the contribution of the TMSCs in the AD skin lesions. Fluorescence microscopy analysis on day 19 revealed that red fluorescent $\mathrm{PKH} 26$ dye gathered around the injected area, indicating that the TMSCs were primarily localized to the injected subcutaneous area (Figure 5). The nuclei were stained with DAPI (blue) in the merged images. Localization of TMSC-PKH26 cells was consistent with DAPI staining. Dead TMSCs were investigated using the TUNEL assay. The injected TMSCs in the DNFB-TMSC7 group survived until 12 days after injection. The DNFB-TMSC16 group showed focal apoptosis of the injected cells.

Immunohistochemistry. We evaluated the expression of IL-6 and TNF- $\alpha$ as proinflammatory cytokines (Figure 6). On day 19 , the DNFB-PBS group showed significantly higher IL-6 expression compared to the other groups (normal, DNFBTMSC7, and DNFB-TMSC16) $(p<0.005)$. TMSC treatment attenuated IL-6 expression, and the DNFB-TMSC16 group demonstrated the lowest level of all groups. TNF- $\alpha$ expression showed a tendency similar to IL-6. The DNFBTMSC7 and DNFB-TMSC16 groups showed decreased 

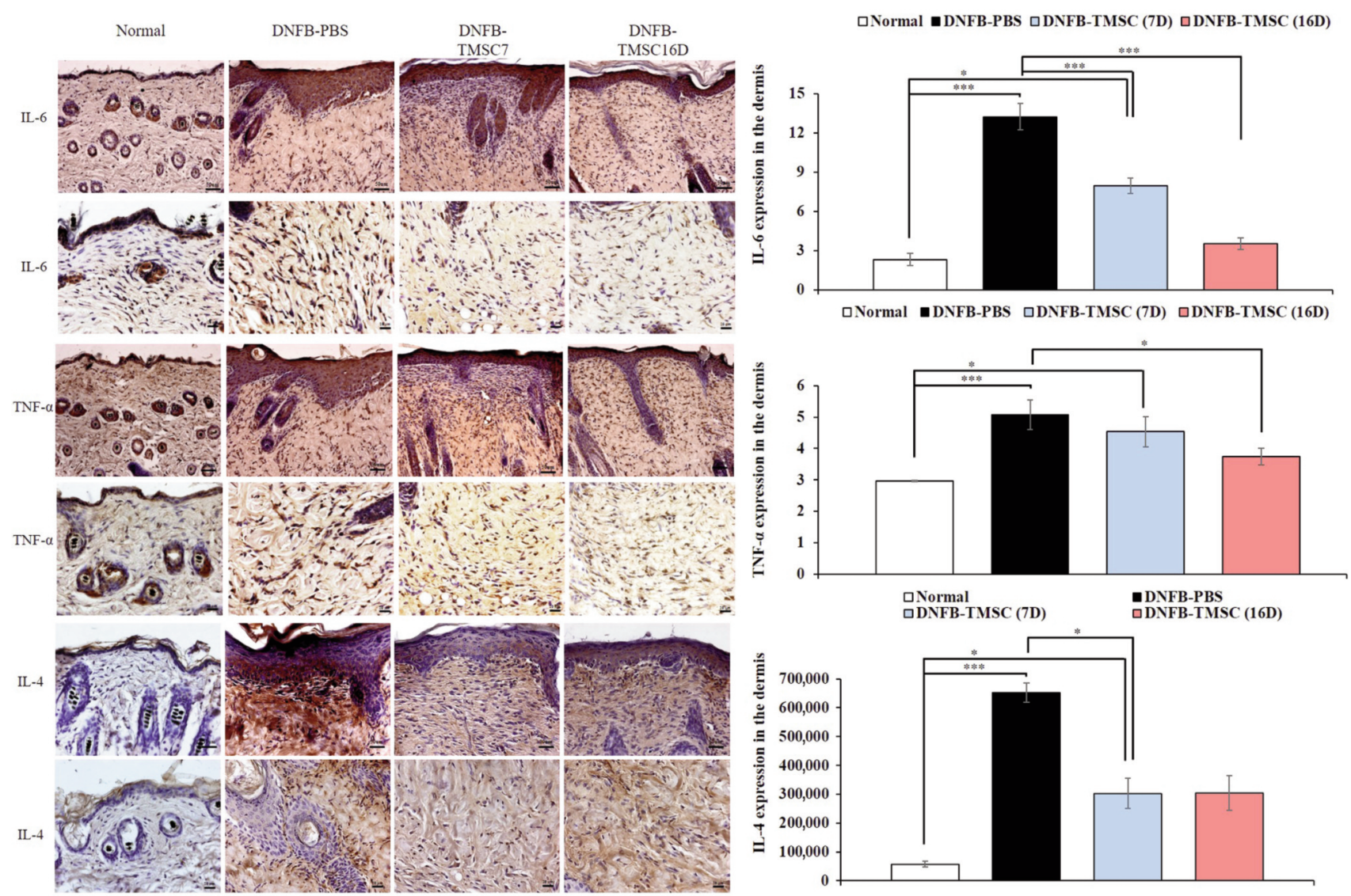

Figure 6. Immunohistochemistry for IL-6, TNF- $\alpha$ and IL-4. Intralesional TMSC injection decreased T-cell derived inflammatory cytokines IL-6, TNF- $\alpha$ (Th1 cell marker), and IL-4 (Th2 cell marker). Bar=50 um (upper panel), Bar=20 um (lower panel). DNFB: 2,4-dinitrofluorobenzene; TMSC: tonsil-derived mesenchymal stem cell. * $p<0.05, * * * p<0.005$.

TNF- $\alpha$ expression compared to the DNFB-PBS group. TMSCs also decreased the Th2 cytokine IL-4 (Figure 6). In contrast, TMSC treatment increased the expression level of the anti-inflammatory cytokine TGF- $\beta$ (Figure 7).

Measurement of serum $\operatorname{IgE}$. Elevated serum $\operatorname{IgE}$ is a hallmark of AD. The DNFB-PBS group showed the highest serum IgE level compared to the normal and TMSC treatment groups. On day 10, three days after TMSC injection, the serum IgE levels in the DNFB-TMSC7 group showed a significant decrease. The DNFB-TMSC16 group also showed a marked decrease in serum $\operatorname{IgE}$ on day 19 , which was three days after the TMSC injection (day 16). However, another increase in $\mathrm{IgE}$ levels was observed in the DNFB-TMSC7 group on day 19. These results indicated that the serum $\mathrm{IgE}$ increase in $\mathrm{AD}$ mice was significantly attenuated by subcutaneous TMSC injection. However, repetitive DNFB challenges after TMSC injection could result in another increase in serum $\operatorname{IgE}$ levels (Figure 8).
LPS-induced inflammatory response: In vitro analysis. NIH3T3 fibroblast cells were stimulated with LPS (25 ng) to investigate whether TMSC treatment produced antiinflammatory efficacy. As expected, LPS stimulation increased the mRNA levels of the inflammatory cytokines TNF- $\alpha$, IL$1 \beta$, and IL-6. In contrast, TMSC treatment significantly decreased the mRNA levels of these three cytokines in LPSstimulated NIH3T3 cells $(p<0.005)$ (Figure 9).

\section{Discussion}

In this study, we demonstrated that subcutaneous administration of the human TMSCs could attenuate DNFBinduced AD-like skin lesions, presumably through the regulation of $\mathrm{B}$ cell-mediated $\mathrm{IgE}$ production and T-cellderived inflammatory responses. We found that intralesional injections of TMSCs induced a significant decrease in allergic skin lesions, mast cell infiltration, $\operatorname{IgE}$ secretion, and the expression of inflammatory cytokines IL6 and TNF- $\alpha$. In 

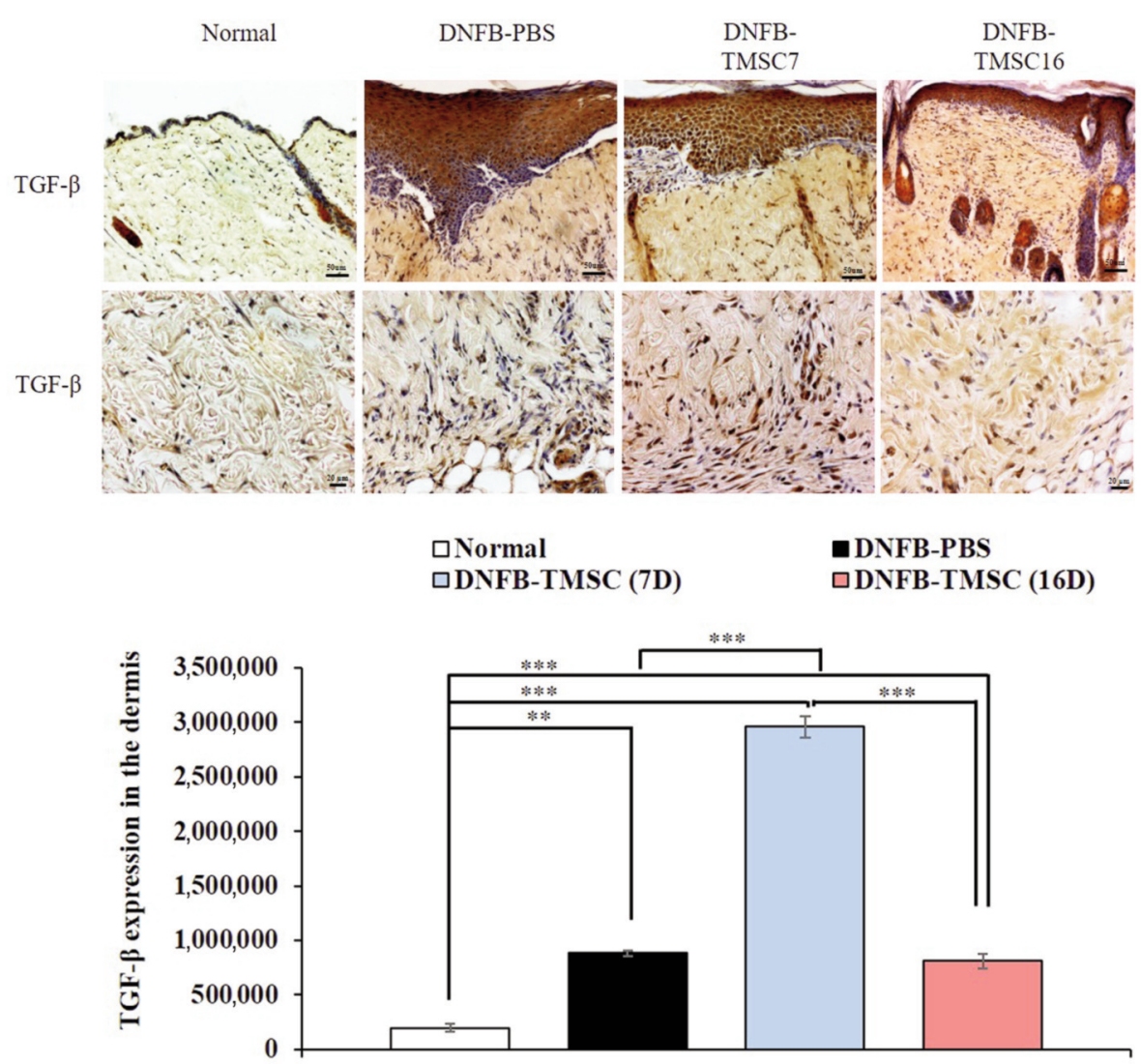

Figure 7. Immunohistochemistry for TGF- $\beta$. Bar=50 um (upper panel), Bar=20 um (lower panel). DNFB: 2,4-Dinitrofluorobenzene; TMSC: tonsilderived mesenchymal stem cell. ${ }^{*} p<0.05,{ }^{* * *} p<0.005$.

addition, TMSC treatment increased the expression of TGF$\beta$, which is considered an immunomodulatory factor.

Atopic dermatitis is an inflammatory skin disorder associated with asthma and allergic rhinitis that reduces the quality of life (21). The current treatment for $\mathrm{AD}$ include topical anti-inflammatory drugs (steroids, tacrolimus), antihistamines, and immunosuppressants. However, it is well known that the continual and long-term use of these medications usually causes side-effects $(2,20)$. Currently, MSC treatment has been suggested as a promising strategy for a variety of immune-mediated diseases and several studies have reported encouraging results with MSCs in the treatment of allergic diseases $(1,10,11,15,16,22)$. Recently, human umbilical cord blood (hUCB)- and adipose tissue (hAT)derived MSCs were reported to alleviate atopic dermatitis (1, $4,10,16)$. In particular, the first clinical trial of hUCB for the treatment of $\mathrm{AD}$ was reported by Kim et al. (4). The underlying mechanisms of MSC effects on the immune system have not been clarified yet. However, it is generally believed that various mechanisms and molecules are related to the immunomodulatory potential of MSCs (11). TMSCs have also shown excellent immune modulatory effects in various disease models including muscular fibrosis (23), skin inflammation (15), B-cell-mediated immune responses (24), and autoimmune-mediated colitis $(25,26)$. In addition, TMSCs were shown to improve allergic rhinitis, an atopic disease (atopic dermatitis, allergic rhinitis, and asthma), by reducing Th2 cytokines and IgE secretion from B cells (11).

As expected, intralesional injection of TMSCs effectively improved AD-like skin lesions and inflammatory parameters in $\mathrm{AD}$ model mice. To explore the protective and therapeutic effects of TMSC, we subcutaneously injected TMSCs at different times. TMSCs were injected on the first day of the DNFB challenge (day 7) in the DNFB-TMSC7 group. After TMSC administration, repetitive DNFB challenges on days 10 and 13 were performed. In contrast, the DNFB-TMSC16 group received TMSC treatment three days after the final DNFB challenge. The current study showed that TMSC treatment rapidly improved the severity of the skin lesions. However, re-challenge with DNFB after TMSC injection seemed to make the skin lesions worse again in the DNFBTMSC7 group. The protective effect of hUCB-derived MSCs 
7 Days
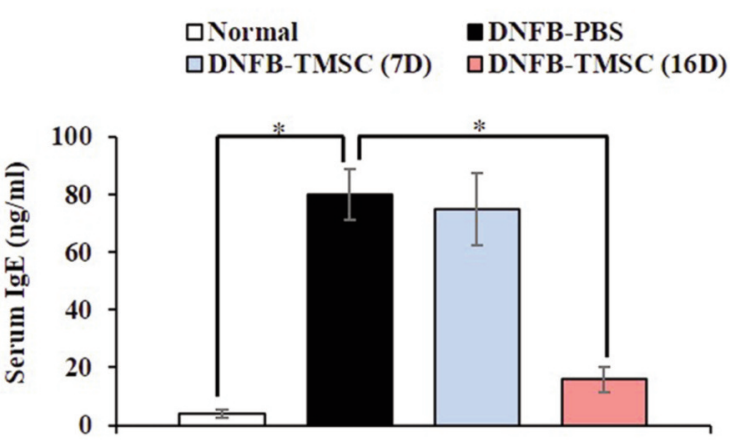

16 Days

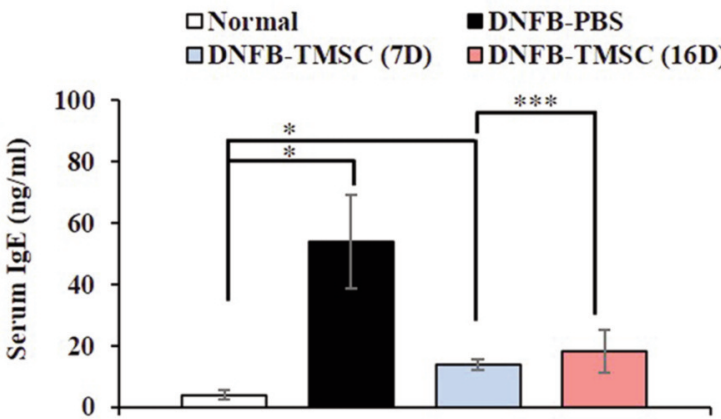

10 Days

aNormal aDFB-PBS

QDNFB-TMSC (7D) QDNFB-TMSC (16D)

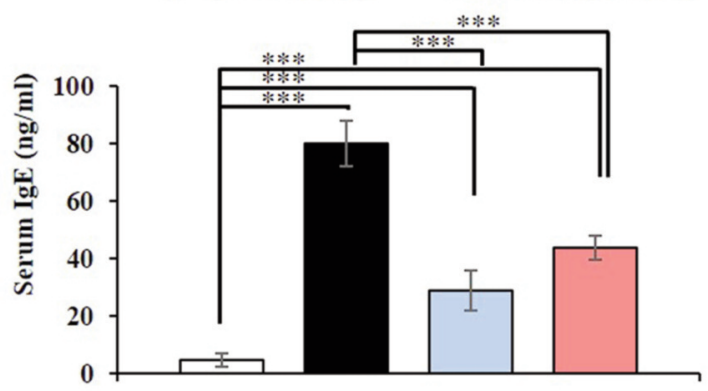

19 Days

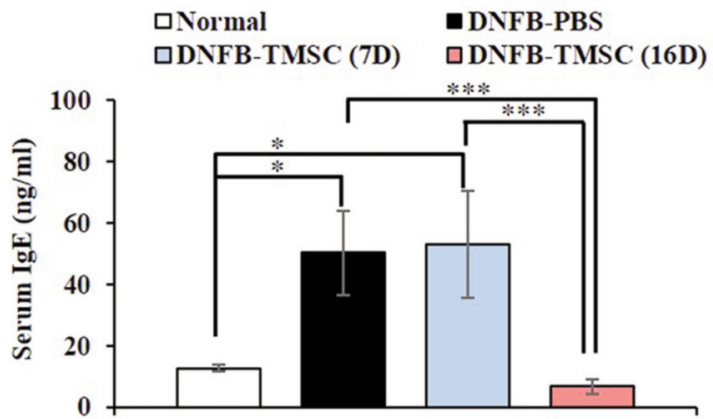

Figure 8. Measurement of serum IgE. Total serum IgE levels were significantly increased by repeated DNFB treatment. Lesional injection of the TMSCs significantly reduced levels of total serum IgE in DNFB-treated mice within 3 days after injection. DNFB: 2,4-Dinitrofluorobenzene; TMSC: tonsil-derived mesenchymal stem cell. $* p<0.05, * * * p<0.005$.

on $\mathrm{AD}$ was demonstrated in a previous study (10). To evaluate the protective effect of hUCB-derived MSCs in that study, cells were injected four times during the experimental period. Our study showed different results from the hUCBderived MSCs, and the difference is presumed to be due to the different number of injections or injected cell numbers. Since the TUNEL assay confirmed that injected TMSCs could survive until 12 days after injection, we could expect that several TMSCs injections or different numbers of injected cells could show a protective effect on AD.

Histology also revealed that hyperplasia of the epidermis and dermal infiltration of mast cells in the DNFB-PBS group were reduced in the TMSC-injected groups, particularly in the DNFB-TMSC16 group compared to the DNFB-TMSC7 group. The TUNEL assay results were also consistent with the histologic results.

Inflammatory cytokines released from activated $\mathrm{T}$ cells determine the maintenance and severity of $\mathrm{AD}$ (27). It has been reported that hUCB-derived MSC extracts suppressed the expression of Th1- (IL-6, IL-1 $\beta$, and TNF- $\alpha$ ) and Th2- (IL-4 and IL-5)-type cytokines in LPS, TNF- $\alpha$, and IFN- $\gamma$-stimulated $\mathrm{HaCaT}$ cells (1). The current study examined the expression of pro- and anti-inflammatory cytokines in the skin tissue of mice. We found that the intralesional injection of TMSCs decreased the expression levels of inflammatory cytokines IL-6 and TNF$\alpha$, as well as Th 2 cytokine IL- 4 . These results indicate that the TMSCs inhibited Th1- and Th2-mediated inflammation. TMSC treatment also significantly down-regulated inflammatory cytokines (IL-6, IL-1 $\beta$, and TNF- $\alpha$ ) after the stimulation of fibroblast cells with LPS in vivo.

$\mathrm{IgE}$ is known to play a major role in the degranulation of mast cells and causes both acute and chronic phase skin symptoms in $\mathrm{AD}$ (3). Consistent with other studies, our results also demonstrated that the total serum $\operatorname{IgE}$ levels were significantly increased by repeated DNFB applications. However, lesional injections of TMSCs significantly decreased the total serum IgE levels in DNFB-treated mice within three days after injection. We also found that repeated DNFB treatment after TMSC injection resulted in another increase in IgE levels. Taken together, the TMSC injection protocol in this study showed effective therapeutic effects on AD. However, a protective effect on AD was not clearly identified.

The underlying anti-allergic mechanisms of TMSCs on AD have not been clarified in this study. However, Samivel et al. 

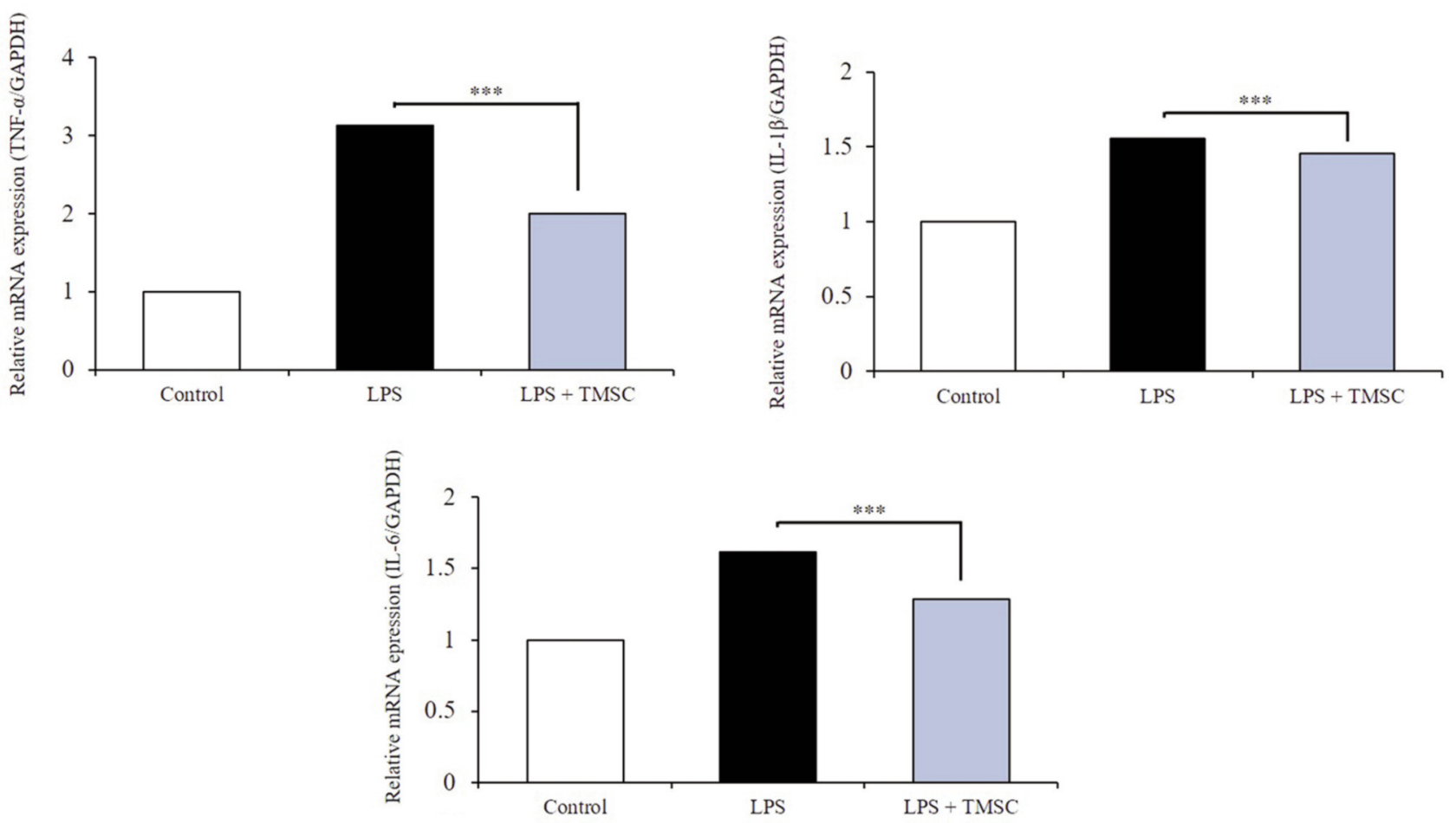

Figure 9. LPS induced inflammatory responses. TMSCs decrease the expression of inflammatory cytokines in LPS-stimulated NIH3T3 fibroblast cells. TMSC: Tonsil-derived mesenchymal stem cell. $* * * p<0.005$.

demonstrated that therapeutic potency of TMSCs on allergic rhinitis could be attributed to inhibition of innate cytokine (IL-25 and IL-33) secretion and of eotaxin expression on the nasal mucosa (11). In addition, supernatant of TMSCs have shown immunomodulatory effect on the allergic rhinitis by the inhibition of $\mathrm{T}$ cell activation via MAP kinas, $\mathrm{p} 65$, and NFAT1 (28). Additional presumed mechanism of therapeutic efficacy of TMSCs on AD is anti-oxidative effect $(29,30)$. An important underlying mechanism that decrease epidermal health and function is keratinocyte damage caused by high levels of intracellular ROS (29). Therefore, antioxidants have been proposed as a skin protector. Recently, antioxidant effects of MSC therapy have been observed in various disease models (30). However, further investigations are needed, including in vitro studies to examine related adverse effects and the molecular mechanisms involved in the anti-allergic effects of TMSCs on AD.

In conclusion, our results indicated that the subcutaneous injection of TMSCs significantly improved inflammatory skin lesions in the DNFB-induced AD mice model, particularly showing therapeutic effects rather than protective effects. Based on the in vitro and in vivo results, the therapeutic potency of TMSCs in AD was attributed to the immunomodulatory effects of the TMSCs. These effects inhibited T-cell and B-cell-mediated inflammatory responses, decreasing the levels of IL-6, IL- $1 \beta$, TNF- $\alpha$ (Th1 cell marker), IL-4 (Th2 cell marker), and serum IgE (B-cell mediated). In contrast, the TMSCs enhanced the antiinflammatory cytokine TGF- $\beta$.

\section{Conflicts of Interest}

The Authors have no conflicts of interest to declare.

\section{Authors' Contributions}

Harry Jung: Methodology, Formal analysis, Investigation, Visualization, Writing original draft; Gil Myeong Son: Methodology, Investigation, Visualization, Validation; Jae Jun Lee: Project administration, Data curation; Hae Sang Park: Conceptualization, Data curation, Supervision, Funding acquisition, Writing review \& editing.

\section{Acknowledgements}

This research was supported by the National Research Foundation of Korea (NRF) grant funded by the Ministry of Science, Information and Communication Technologies and Future Planning of the Korea government (NRF-2017M3A9E8033206); the National Research Foundation of Korea (NRF) grant funded by the Korea government (NRF-2017R1D1A1B04034145); the Hallym University Research Fund. 


\section{References}

1 Song JY, Kang HJ, Ju HM, Park A, Park H, Hong JS, Kim CJ, Shim JY, YuJ and Choi J: Umbilical cord-derived mesenchymal stem cell extracts ameliorate atopic dermatitis in mice by reducing the $\mathrm{T}$ cell responses. Sci Rep 9: 6623, 2019. PMID: 31036853. DOI: 10.1038/s41598-019-42964-7

2 Katoh N, Ohya Y, Ikeda M, Ebihara T, Katayama I, Saeki H, Shimojo N, Tanaka A, Nakahara T, Nagao M, Hide M, Fujita Y, Fujisawa T, Futamura M, Masuda K, Murota H, and YamamotoHanada K: Japanese guidelines for atopic dermatitis 2020. Allergol Int 69(3): 356-369, 2020. PMID: 32265116. DOI: 10.1016/j.alit.2020.02

3 Kim TH, Jung JA, Kim GD, Jang AH, Ahn HJ, Park YS and Park CS: Melatonin inhibits the development of 2,4dinitrofluorobenzene-induced atopic dermatitis-like skin lesions in NC/Nga mice. J Pineal Res 47(4): 324-329, 2009. PMID: 19817972. DOI: 10.1111/j.1600-079X.2009.00718.x

4 Kim HS, Lee JH, Roh KH, Jun HJ, Kang KS and Kim TY: Clinical trial of human umbilical cord blood-derived stem cells for the treatment of moderate-to-severe atopic dermatitis: Phase I/IIa studies. Stem Cells 35(1): 248-255, 2017. PMID: 27256706. DOI: $10.1002 /$ stem. 2401

5 Jin H, He R, Oyoshi M and Geha RS: Animal models of atopic dermatitis. J Invest Dermatol 129(1): 31-40, 2009. PMID: 19078986. DOI: $10.1038 /$ jid.2008.106

6 Kim J, Kim BE and Leung DYM: Pathophysiology of atopic dermatitis: Clinical implications. Allergy Asthma Proc 40(2): 8492, 2019. PMID: 30819278. DOI: 10.2500/aap.2019.40.4202

7 Kim GD, Kim TH, Park YS, Ahn HJ, Cho JJ and Park CS: Immune response against 2,4-dinitrofluorobenzene-induced atopic dermatitis-like clinical manifestation is suppressed by spermidine in NC/Nga mice. Scand J Immunol 81(4): 221-228, 2015. PMID: 25645543. DOI: 10.1111/sji.12274

8 Luque-Campos N, Contreras-López RA, Paredes-Martínez MJ, Torres MJ, Bahraoui S, Wei M, Espinoza F, Djouad F, ElizondoVega RJ and Luz-Crawford P: Mesenchymal stem cells improve rheumatoid arthritis progression by controlling memory $\mathrm{T}$ cell response. Front Immunol 16(10): 798, 2019. PMID: 31040848. DOI: $10.3389 /$ fimmu. 2019.00798

9 Song EM, Jung SA, Lee KE, Jang JY, Lee KH, Tae CH, Moon CM, Joo YH, Kim SE, Jung HK and Shim KN: The Therapeutic efficacy of tonsil-derived mesenchymal stem cells in dextran sulfate. Korean J Gastroenterol 69(2): 119-128, 2017. PMID: 28239080. DOI: 10.4166/kjg.2017.69.2.119

10 Kim HS, Yun JW, Shin TH, Lee SH, Lee BC, Yu K, Seo Y, Lee S, Kang T, Choi SW, Seo K and Kang KS: Human umbilical cord blood mesenchymal stem cell-derived PGE2 and TGF- $\beta 1$ alleviate atopic dermatitis by reducing mast cell degranulation. Stem Cells 2: 1254-1266, 2015. PMID: 25522163. DOI: 10.1002/stem.1913

11 Samivel R, Kim EH, Chung YJ and Mo JH: Immunomodulatory effect of tonsil-derived mesenchymal stem cells in a mouse model of allergic rhinitis. Am J Rhinol Allergy 29(4): 262-267, 2015. PMID: 26085003. DOI: 10.2500/ajra.2015.29.4216

12 Bačić A, Prgomet D and Janjanin S: Tonsil-derived mesenchymal stem cells exert immunosuppressive effects on T cells. Croat Med J 60(1): 12-19, 2019. PMID: 30825273. DOI: $10.3325 / \mathrm{cmj} .2019 .60 .12$

13 Ryu KH, Cho KA, Park HS, Woo SY, Park YS, Jo IH, Choi YH, Park YM, Jung S, Chung SM, Choi B and Kim HS: Tonsil- derived mesenchymal stem cells: Evaluation of biological, immunological, and genetic factors for successful banking. Cytotherapy 14(10): 1193-1202, 2012. PMID: 22900958. DOI: 10.3109/14653249.2012.706708

14 Park HS, Lee J, Kim JW, Kim HY, Jung SY, Lee SM, Park CH and Kim HS: Preventive effects of tonsil-derived mesenchymal stem cells on osteoradionecrosis in a rat model. Head Neck 40(3): 526-535, 2018. PMID: 29140591. DOI: 10.1002/hed.25004

15 Kim JY, Park M, Kim YH, Ryu KH, Lee KH, Cho KA and Woo $\mathrm{S}$ : Tonsil-derived mesenchymal stem cells (T-MSCs) prevent Th17-mediated autoimmune response via regulation of the programmed death-1/programmed death ligand-1 (PD-1/PD-L1) pathway. J Tissue Eng Regen Med 12(2): e1022-1033, 2018. PMID: 28107610. DOI: 10.1002/term.2423

16 Shin TH, Lee BC, Choi SW, Shin JH, Kang I, Lee JY, Kim J, Lee HK, Jung J, Choi Y, Lee S, Yoon J, Choi J, Lee C, Seo Y, Kim $\mathrm{H}$ and Kang $\mathrm{K}$ : Human adipose tissue-derived mesenchymal stem cells alleviate atopic dermatitis via regulation of B lymphocyte maturation. Oncotarget 8(1): 512-522, 2017. PMID: 27888809. DOI: 10.18632/oncotarget.13473

17 Li J, Shen C, Liu Y, Li Y, Sun L, Jiao L, Jiao W, Xiao J, Shen $\mathrm{C}, \mathrm{Qi} \mathrm{H}, \mathrm{Xu} \mathrm{F}$ and $\mathrm{Ma} \mathrm{L}$ : Impaired function of CD5+CD19+CD1dhi B10 cells on IgE secretion in an atopic dermatitis-like mouse model. PLoS One 10(8): 1-11, 2015. PMID: 26244559. DOI: 10.1371/journal.pone.0132173

18 Vaia M, Petrosino S, De Filippis D, Negro L, Guarino A, Carnuccio R, Marzo VD and Iuvone T: Palmitoylethanolamide reduces inflammation and itch in a mouse model of contact allergic dermatitis. Eur J Pharmacol 15(79): 669-674, 2016. PMID: 27720681. DOI: 10.1016/j.ejphar.2016.10.005

19 Lee JH, Lee YS, Lee EJ and Kim TY: Capsiate Inhibits DNFBInduced Atopic Dermatitis in NC/Nga Mice through Mast Cell and CD4+ T-Cell Inactivation. J Invest Dermatol 135(8): 19771985, 2015. PMID: 25806854. DOI: 10.1038/jid.2015.117

20 Hong SH, Ku JM, Kim HI, Kim TY, Seo HS, Shin YC and Ko S: Topical application of KajD attenuates 2,4-dinitrochlorobenzene-induced atopic dermatitis symptoms through regulation of IgE and MAPK pathways in BALB/c mice and several immune cell types. Front Pharmacol 19(10): 1097, 2019. PMID: 31607928. DOI: 10.3389/fphar.2019.01097

21 Zheng $\mathrm{T}$, Yu J, Oh MH and Zhu Z. The atopic march: Progression from atopic dermatitis to allergic rhinitis and asthma. Allergy Asthma Immunol Res 3(2): 67-73, 2011. PMID: 21461244. DOI: 10.4168/aair.2011.3.2.67

22 Nemeth K, Keane-Myers A, Brown JM, Metcalfe DD, Gorham JD, Bundoc VG, Hodges MG, Jelinek I, Madala S, Karpati S and Mezey E: Bone marrow stromal cells use TGF- $\beta$ to suppress allergic responses in a mouse model of ragweed-induced asthma. Proc Natl Acad Sci USA 107(12): 5652-5657, 2010. PMID 20231466. DOI: 10.1073/pnas.0910720107

23 Cho KA, Park M, Kim YH, Woo SY and Ryu KH: Conditioned media from human palatine tonsil mesenchymal stem cells regulates the interaction between myotubes and fibroblasts by IL-1Ra activity. J Cell Mol Med 21(1): 130-141, 2017. PMID: 27619557. DOI: $10.1111 / \mathrm{jcmm} .12947$

24 Cho KA, Lee JK, Kim YH, Park M, Woo SY and Ryu KH: Mesenchymal stem cells ameliorate B-cell-mediated immune responses and increase IL-10-expressing regulatory B cells in an EBI3-dependent manner. Cell Mol Immunol 14(11): 895-908, 2017. PMID: 28042143. DOI:10.1038/cmi.2016.59 
25 Yu Y, Song EM, Lee KE, Joo YH, Kim SE, Moon CM, Kim HY, Jung $S$ and Jo I: Therapeutic potential of tonsil-derived mesenchymal stem cells in dextran sulfate sodium-induced experimental murine colitis. PLoS One 12(8): 1-18, 2017. PMID: 28854223. DOI: 10.1371/journal.pone.0183141

26 Cho KA, Lee HJ, Jeong H, Kim M, Jung SY, Park HS, Ryu KH, Lee SJ, Jeong B, Lee H and Kim HS: Tonsil-derived stem cells as a new source of adult stem cells. World J Stem Cells 11(8): 506-518, 2019. PMID: 31523370. DOI: 10.4252/wjsc.v11.i8.506

27 Purushothaman B, Arumugam P and Song JM: A novel catecholopyrimidine based small molecule PDE4B inhibitor suppresses inflammatory cytokines in atopic mice. Front Pharmacol 11(9): 1-11, 2018. PMID: 29867490. DOI: 10.3389/ fphar.2018.00485

28 Park IS, Kim JH, Bae JS, Kim D and Mo J: The supernatant of tonsil-derived mesenchymal stem cell has antiallergic effects in allergic rhinitis mouse model. Mediators Inflamm 7: 6982438, 2020. PMID: 32322164. DOI: $10.1155 / 2020 / 6982438$
29 Chowjarean V, Prueksasit T, Joyjamras K and Chanvorachote P: Isovitexin increases stem cell properties and protects against PM2.5 in keratinocytes. In Vivo 33(6): 1833-1841, 2019. PMID: 31662510. DOI: 10.21873 /invivo.11676

30 Stavely R and Nurgali K: The emerging antioxidant paradigm of mesenchymal stem cell therapy. Stem Cells Transl Med 9(9): 985-1006, 2020. PMID: 32497410. DOI: 10.1002/sctm.19-0446

Received November 4, 2020

Revised December 28, 2020

Accepted January 8, 2021 